\title{
THE OCCURRENCE OF DIURESIS IN HUMANS IN STRESSFUL SITUATIONS AND ITS POSSIBLE RELATION TO THE DIURESIS OF EARLY STARVATION
}

\author{
By LAWRENCE E. HINKLE, JR., CLIFFORD J. EDWARDS, AND STEWART WOLF \\ WITH THE TECHNICAL ASSISTANCE OF GEORGE B. CONGER, BETTY L. PUGH, \\ AND MARY ANNE KENNEDY \\ (From the Department of Medicine of the New York Hospital-Cornell Medical Center, \\ New York, N.Y.)
}

(Submitted for publication November 24, 1950; accepted May 7, 1951)

It is a common clinical observation that persons involved in stressful situations associated with feelings of anxiety and apprehension may have frequency of urination. Whether this phenomenon is the result of the ingestion of water, reflex irritability of the bladder, or a true polyuria of undetermined origin has not been entirely clear. That stimuli acting through the central nervous system may affect the rate at which the kidney excretes urine is well known. Rydin and Verney $(1,2)$ have shown that a water diuresis in dogs may be inhibited by the stimulation of afferent nerves or by loud noises. Kelsall (3), Wolf (4), and Odell and Aragon (5) have demonstrated a similar phenomenon in humans in reaction to pain. On the other hand "emotional diuresis" has also been observed experimentally (6). Marx (7), Heilig and Hoff (8), and Hoff and Wermer (9), have reported the induction of diuresis by hypnotic suggestion. Marx later reported (10) that he had succeeded in conditioning one of four dogs to a reflex diuresis after sham drinking. Bykow and Alexejew-Berkmann (11) also reported a conditional reflex diuresis in dogs, and Eagle (12) was able to condition animals to a reflex inhibition of diuresis after the ingestion of water. Anderson (13) observed a soldier with an ureteral fistula from which an increased urine flow could be produced by various "psychic" stimuli, and Rooke (14) stated that he has repeatedly observed an increased flow from ureteral catheters when patients were told to think about drinking beer or tea. Sheba observed that during an eight hour period soldiers, in expectation of going "over the line," excreted as much as 4 liters of urine with a specific gravity near 1.000 (15). A diuresis has been observed to occur in persons with diabetes mellitus under circumstances of environmental stress (16, 17 ), and it is well known that a transient diuresis accompanies the first stages of a total fast (18, $19)$. Both of these phenomena are temporally associated with changes in fat and carbohydrate metabolism. The present study concerns the experimental production of a water diuresis in humans during stressful situations. To provide an indication of other metabolic changes occurring at the same time, simultaneous measurements of blood glucose and blood ketone bodies were made throughout the experimental period.

\section{METHODS}

Subjects for this study were patients from the Medical Clinic of the New York Hospital with minor disorders such as functional diarrhea and headache, and volunteers from the hospital staff. Subjects were selected who were known to be reliable and intelligent persons, and who had been observed to develop anxiety under certain circumstances, especially in connection with some of their personal conflicts. Such persons made up both the stress and control groups. In none of the subjects was there any evidence of renal disease or other pathological processes known to interfere with kidney function. The patients were subjected to a prolonged study which included a medical history, physical examination, and indicated laboratory procedures, as well as an evaluation of their personality structures, life histories, cultural backgrounds, present life situations, and significant conscious and unconscious conflicts. The manner in which these studies were made has been described elsewhere (16).

Experiments were performed in the morning after an overnight fast. Except as noted in the protocols, subjects had ingested no fluids since the evening before. Muscular activity prior to the experimental period was limited to that involved in walking or riding to the laboratory. No smoking was allowed during the experiment. On arising the subject noted the time at which he emptied his bladder; when he arrived at the laboratory he again emptied his bladder, and the time was recorded. Observations were made during three periods of approximately one hour thereafter. During the first and third hours the subject amused himself reading books or magazines, or was engaged in neutral discussion with the interviewer. During the middle hour he was engaged in a 
vigorous discussion of topics of significant personal conflict known to be associated with strong and conflicting conscious and unconscious attitudes and feelings.

The reaction of each subject to the procedure was evaluated by observation of his behavior, including both overt manifestations such as facial expression, content of remarks, tone of voice, tears, tachycardia, and sweating, as well as the more subtle clues such as slips of the tongue, figures of speech, and fleeting gestures, which gained significance for the observer from his past familiarity with the subject. The statements of the subject during the interview were recorded, and at later interviews the data were supplemented by his recollections and associations concerning all three of the experimental hours. This precaution was necessary since it could not be assumed that because he was apparently quietly and contentedly reading a magazine during the control hours that he was therefore "relaxed" and not reacting to his environment with significant attitudes and emotions.

The control procedures which were carried out were identical to those described above except that no stressful topics were discussed. Because laboratory procedures such as these may in themselves have threatening implications for some people, and because subjects may them- selves introduce a stressful stimulus into an intended control procedure through their own ruminations, the subjects for the control procedures were studied as carefully before, during, and after the procedure as the subjects who were exposed to stressful interviews, and their experiences were as carefully evaluated.

Urine chlorides were measured by the method of Sendroy (20). Blood and urine ketones were determined by a macro-modification of the micro-method of Greenberg and Lester (21-23). Urine glucose was measured by the method of Benedict (24). Blood glucose determinations were made on filtrates prepared by the method of Herbert and Bourne (25), using one of Benedict's copper reagents (26-28); this method closely approximates "true blood glucose," excluding other reducing substances. Urine specific gravity was determined with a calibrated clinical hygrometer. Eosinophile counts were made after the manner described by Thorn and associates (29).

\section{RESULTS}

\section{Control Studies}

Because major changes in physical activity and in posture are known to affect the rate of excre-

TABLE I

Rate of water excretion, $c c /$ min.

Control studies

\begin{tabular}{|c|c|c|c|c|c|c|c|c|c|c|c|}
\hline & \multirow{2}{*}{ Subj. } & \multirow{2}{*}{ Sex } & \multirow{2}{*}{ Age } & \multirow{2}{*}{$\begin{array}{l}\text { Position and } \\
\text { activity }\end{array}$} & \multirow{2}{*}{ Fluid intake } & \multirow{2}{*}{$\begin{array}{l}\text { Before } \\
\text { arrival }\end{array}$} & \multicolumn{3}{|c|}{ Observation periods } & \multirow{2}{*}{$\underset{\mathrm{cc} / \mathrm{min}}{\Delta}$} & \multirow{2}{*}{$\stackrel{\Delta}{\%}$} \\
\hline & & & & & & & 1 st hr. & 2nd hr. & 3rd hr. & & \\
\hline $\begin{array}{l}1 . \\
2 . \\
3 . \\
4 . \\
5 . \\
6 .\end{array}$ & $\begin{array}{r}\mathrm{XH} \\
\mathrm{D} \\
\mathbf{X A} \\
\mathbf{D} \\
\mathbf{X G} \\
\mathbf{A}\end{array}$ & $\begin{array}{l}\mathbf{F} \\
\mathbf{F} \\
\mathbf{F} \\
\mathbf{F} \\
\mathbf{M} \\
\mathbf{F}\end{array}$ & $\begin{array}{l}25 \\
22 \\
23 \\
22 \\
21 \\
20\end{array}$ & $\begin{array}{l}\text { Standing and } \\
\text { walking about }\end{array}$ & None & $\begin{array}{l}\overline{-} \\
\overline{0.9} \\
1.1 \\
-\end{array}$ & $\begin{array}{l}0.2 \\
0.4 \\
0.6 \\
0.4 \\
1.2 \\
0.6\end{array}$ & $\begin{array}{l}0.2 \\
0.4 \\
0.7 \\
0.3 \\
1.2 \\
0.5\end{array}$ & $\begin{array}{l}0.2 \\
0.3 \\
2.1^{*} \\
0.3 \\
1.1 \\
0.4\end{array}$ & $\begin{array}{r}0.00 \\
+0.05 \\
-0.65 \\
-0.05 \\
+0.05 \\
0.00\end{array}$ & $\begin{array}{r}0 \\
+14 \\
-48 \\
-14 \\
+4 \\
0\end{array}$ \\
\hline $\begin{array}{r}7 . \\
8 . \\
9 . \\
10 . \\
11 .\end{array}$ & $\begin{array}{r}\mathbf{C} \\
\mathbf{X} \\
\underset{B}{E}\end{array}$ & $\begin{array}{l}\mathbf{M} \\
\mathbf{F} \\
\mathbf{F} \\
\mathbf{M} \\
\mathbf{F}\end{array}$ & $\begin{array}{l}31 \\
30 \\
35 \\
35 \\
30\end{array}$ & $\begin{array}{l}\text { Sitting; clerical } \\
\text { work }\end{array}$ & None & $\begin{array}{l}0.4 \\
0.3 \\
0.3 \\
- \\
-\end{array}$ & $\begin{array}{l}0.5 \\
0.4 \\
0.9^{*} \\
0.5 \\
0.5\end{array}$ & $\begin{array}{l}0.5 \\
0.3^{*} \\
1.3^{*} \\
0.9^{*} \\
0.3\end{array}$ & $\begin{array}{l}0.4 \\
0.4 \\
2.3^{*} \\
1.1^{*} \\
0.2\end{array}$ & $\begin{array}{r}+0.05 \\
-0.10 \\
-0.30 \\
+0.10 \\
-0.05\end{array}$ & $\begin{array}{l}+10 \\
-25 \\
-19 \\
+12 \\
-11\end{array}$ \\
\hline $\begin{array}{l}12 . \\
13 .\end{array}$ & $\begin{array}{l}\text { AD } \\
\text { XC }\end{array}$ & $\mathbf{F}$ & $\begin{array}{l}60 \\
28\end{array}$ & Lying in bed & None & $\begin{array}{l}1.0 \\
0.6\end{array}$ & $\begin{array}{l}0.7 \\
0.6\end{array}$ & $\begin{array}{l}0.7 \\
0.5\end{array}$ & $\begin{array}{l}0.7 \\
0.7\end{array}$ & $\begin{array}{r}0.00 \\
-0.15\end{array}$ & $\begin{array}{r}0 \\
-23\end{array}$ \\
\hline $\begin{array}{l}14 . \\
15 . \\
16 . \\
17 . \\
18 . \\
19 . \\
20 . \\
21 . \\
22 . \\
23 . \\
24 .\end{array}$ & $\begin{array}{c}\mathbf{A X} \\
\mathbf{A W} \\
\mathbf{X J} \\
\mathbf{C} \\
\mathbf{X} \\
\mathbf{X} \\
\mathbf{X E} \\
\mathbf{B} \\
\mathbf{X} \\
\mathbf{X} \\
\mathbf{E} \\
\mathbf{E}\end{array}$ & $\begin{array}{l}\mathbf{F} \\
\mathbf{M} \\
\mathbf{F} \\
\mathbf{M} \\
\mathbf{F} \\
\mathbf{F} \\
\mathbf{F} \\
\mathbf{F} \\
\mathbf{M} \\
\mathbf{F} \\
\mathbf{M}\end{array}$ & $\begin{array}{l}42 \\
45 \\
29 \\
31 \\
27 \\
40 \\
30 \\
30 \\
30 \\
40 \\
35\end{array}$ & $\begin{array}{l}\text { Sitting, 1st and } \\
\text { 3rd hrs.; ly- } \\
\text { ing, 2nd hr. }\end{array}$ & $\begin{array}{c}\text { None } \\
\text { None } \\
\text { None } \\
60 \mathrm{cc} \text { i.v. 2nd hr. } \\
60 \mathrm{cc} \text { i.v. 2nd hr. } \\
60 \mathrm{cc} \text { i.v. 2nd hr. } \\
60 \mathrm{cc} \text { i.v. 2nd hr. } \\
125 \text { cc i.v. 2nd hr. } \\
125 \text { cc i.v. 2nd hr. } \\
125 \text { cc i.v. 2nd hr. } \\
125 \text { cc i.v. 2nd hr. }\end{array}$ & $\begin{array}{l}0.6 \\
0.6 \\
0.5 \\
0.8 \\
1.8 \\
0.6 \\
0.4 \\
0.6 \\
1.0\end{array}$ & $\begin{array}{l}0.4 \\
0.9 \\
0.8 \\
0.5 \\
0.8 \\
1.1 \\
0.5 \\
0.6 \\
0.4 \\
0.7 \\
0.6\end{array}$ & $\begin{array}{l}0.3 \\
0.9 \\
0.7 \\
0.6 \\
1.0 \\
0.8 \\
0.7 \\
0.6 \\
0.4 \\
0.8 \\
0.9\end{array}$ & $\begin{array}{l}0.2 \\
0.6 \\
0.5 \\
0.5 \\
0.9 \\
0.7 \\
0.7 \\
0.7 \\
0.5 \\
1.3^{*} \\
0.8\end{array}$ & $\begin{array}{l}0.0 \\
+0.15 \\
+0.05 \\
+0.10 \\
+0.15 \\
-0.10 \\
+0.10 \\
-0.05 \\
-0.05 \\
-0.20 \\
+0.20\end{array}$ & $\begin{array}{r}0 \\
+20 \\
+8 \\
+20 \\
+18 \\
-11 \\
+17 \\
-8 \\
-11 \\
-20 \\
+22\end{array}$ \\
\hline
\end{tabular}

$\Delta \mathrm{cc} / \mathrm{min}$. , mean : -0.029

$\Delta \%$, mean: -0.04

Standard error of mean $\pm \mathbf{0 . 0 3 6}$

Standard error of mean \pm 3.6

- Figures marked with an asterisk represent hours during which subjects experienced marked hunger.

"Delta" in each control study represents the difference between the values obtained during the first and third hours and those obtained during the interview hour. It is obtained by subtracting the average of the values obtained during the first and third hours from that obtained during the second hour. 
TABLE II

Rate of water excretion, $c c /$ min.

Stress studies

(stressful interview 2nd hr.)

\begin{tabular}{|c|c|c|c|c|c|c|c|c|c|c|c|}
\hline & \multirow{2}{*}{ Subj. } & \multirow{2}{*}{ Sex } & \multirow{2}{*}{ Age } & \multirow{2}{*}{$\begin{array}{l}\text { Position and } \\
\text { activity }\end{array}$} & \multirow{2}{*}{ Fluid intake } & \multirow{2}{*}{$\begin{array}{l}\text { Before } \\
\text { arrival }\end{array}$} & \multicolumn{3}{|c|}{ Observation periods } & \multirow{2}{*}{$\underset{c / m i n}{\Delta}$} & \multirow{2}{*}{$\stackrel{\Delta}{\%}$} \\
\hline & & & & & & & 1st hr. & 2nd hr. & $3 \mathrm{rd} \mathrm{hr}$. & & \\
\hline 1. & $\mathbf{X I}$ & F & 32 & & None & 0.3 & 0.8 & 2.1 & 0.6 & +1.40 & +175 \\
\hline $\begin{array}{r}2 . \\
3 . \\
4 . \\
5 . \\
6 . \\
7 . \\
8 . \\
9 . \\
10 . \\
11 . \\
12 .\end{array}$ & $\begin{array}{l}\text { AX } \\
\text { BF } \\
\text { AW } \\
\text { XJ } \\
\text { XK } \\
\text { XJ } \\
\text { XO } \\
\text { XK } \\
\mathbf{H} \\
\mathbf{G} \\
\mathbf{F}\end{array}$ & $\begin{array}{l}\mathbf{F} \\
\mathbf{M} \\
\mathbf{M} \\
\mathbf{F} \\
\mathbf{F} \\
\mathbf{F} \\
\mathbf{F} \\
\mathbf{F} \\
\mathbf{F} \\
\mathbf{F} \\
\mathbf{F}\end{array}$ & $\begin{array}{l}42 \\
15 \\
45 \\
29 \\
38 \\
29 \\
40 \\
38 \\
27 \\
36 \\
33\end{array}$ & $\begin{array}{l}\text { Sitting, 1st and } \\
\text { 3rd hrs.; ly- } \\
\text { ing, 2nd hr. }\end{array}$ & $\begin{array}{c}\text { None } \\
\text { None } \\
\text { None } \\
\text { None } \\
\text { None } \\
\text { None } \\
\text { None } \\
\text { None } \\
40 \mathrm{cc} \text { i.v. 2nd hr. } \\
60 \text { cc i.v. 2nd hr. } \\
200 \text { cc P.O. 1st- } \\
\text { 3rd hrs. 100 cc } \\
\text { i.v. 2nd hr. }\end{array}$ & $\begin{array}{l}0.2 \\
0.3 \\
2.3 \\
1.0 \\
0.9 \\
2.6 \\
1.4 \\
0.3 \\
= \\
-\end{array}$ & $\begin{array}{l}2.7 \\
0.4 \\
2.5 \\
1.2 \\
3.3 \\
1.6 \\
2.5 \\
1.2 \\
0.8 \\
1.1 \\
1.0\end{array}$ & $\begin{array}{l}2.0 \\
0.8 \\
1.5 \\
2.7 \\
4.5 \\
3.0 \\
1.8 \\
3.2 \\
2.9 \\
2.1 \\
5.1\end{array}$ & $\begin{array}{l}0.5 \\
1.0 \\
0.8 \\
1.0 \\
1.3 \\
0.6 \\
0.9 \\
1.2 \\
1.5 \\
0.2 \\
2.0\end{array}$ & $\begin{array}{l}+2.20 \\
+0.10 \\
+1.70 \\
+1.60 \\
+3.20 \\
+2.40 \\
+1.60 \\
+2.00 \\
+1.75 \\
+1.45 \\
+3.60\end{array}$ & $\begin{array}{l}+440 \\
+14 \\
+212 \\
+144 \\
+246 \\
+400 \\
+178 \\
+167 \\
+152 \\
+223 \\
+240\end{array}$ \\
\hline
\end{tabular}

$\Delta \mathrm{cc} / \mathrm{min}$. , mean $:+1.92$

$\Delta \%$, mean: +216

Standard error of mean \pm 0.26

$\Delta \mathrm{cc} / \mathrm{min}$., mean difference between means of stress and control studies,

$1.95 \pm 0.26 \quad P<0.001$

$\Delta \%$, mean difference between means of stress and control studies, $216 \pm 32.9 \quad P<0.01$

Values in bold type are those obtained during hours in which the subjects were anxious and apprehensive.

In stress studies "Delta" was obtained by subtracting the average of the values obtained during the hours in which the subjects were not apprehensive from the highest value during the hours in which they were anxious and apprehensive.

tion of water, and because it is impossible to prevent some change in position and activity from occurring in patients during interviews of this sort, control studies were made on subjects in a wide variety of positions and during various degrees of light activity. As seen in Table I, subjects were tested while lying in bed, sitting, standing, and walking about, doing laboratory or clerical work, all or part of the time. It was found that such minor variations in activity had no noticeable effect upon the urine output of these subjects. In those in whom an accurate estimation of the rate of urine formation could be made from the time they arose until they arrived at the laboratory, it was found that the rate of urine formation prior to the test was not significantly different from that during the three hours of observation. Because of the known diurnal variations in human urine volume, all of the studies were made between 9 a.m. and 1 p.m., beginning two to three hours after the subject had arisen from bed. The only exceptions to this were the two studies (stress and control) on subject $H$ and the stress study on subject $F$, which were made in the afternoon.

In a few of the subjects, in order to facilitate the collection of blood samples at frequent intervals during the stress interview, a continuous slow intravenous drip of $0.9 \%$ saline at the rate of approximately $1 \mathrm{cc} / \mathrm{min}$. was maintained during this time through an indwelling needle. The total amount administered was 60 to $100 \mathrm{cc}$. In view of the possible diuretic effect of this procedure similar intravenous injections were given to some of the control subjects. In these individuals, however, diuresis was never observed with as much as 125 cc of saline administered intravenously during the course of an hour while the subjects were supine.

In none of the control subjects was there significant change in the urine specific gravity or in the rate of excretion of water, chlorides, and ketone bodies, during the hour of the neutral interview as compared to the control hours, although a slight and steady rise or fall in the various excretion rates during the three hours sometimes occurred. The rate of water excretion lay between 0.2 and 1.1 $\mathrm{cc} / \mathrm{min}$. (Table I), the rate of chloride excretion lay between 2.1 and $9.7 \mathrm{mg} / \mathrm{min}$., and the rate of ketone excretion lay between 0.005 and $0.049 \mathrm{mg} /$ min. (expressed as acetone recovered). A $10 \%$ 
to $40 \%$ fall in circulating eosinophiles occurred in most subjects during the course of the morning.

In 20 of the 24 studies these excretion rates, as well as the urine specific gravity, changed very little throughout the morning (Table III). The concentration of the ketone bodies and of glucose in the blood of these subjects also remained approximately constant. This point is not illustrated in the tables, but is dealt with elsewhere (23, 30). The protocol of one of these studies is diagrammed in Figure 1. The slight but steady fall in the blood glucose and the slight but steady rise in the circulating ketones which usually occur during a morning's fast were accompanied by relatively little change in the rate of excretion of water, chlorides, and ketones, and no consistent change in the concentration of these substances in the urine. In four of the subjects, however, there occurred an increase in the urine volume during the later
TABLE III

Summary of changes observed in other urinary constituents

Chlorides (expressed as $\mathrm{NaCl}$ )

Concentrations:

$\Delta \mathrm{mg} \%$, mean of control studies: $+50 \pm 33$

$\Delta \mathrm{mg} \%$, mean of stress studies: $-377 \pm 75$

Mean difference: $427 \pm 82 \quad P<0.005$

Rates:

$\Delta \mathrm{mg} / \mathrm{min}$., mean of control studies: $\quad 0.0 \pm 0.5$

$\Delta \mathrm{mg} / \mathrm{min}$., mean of stress studies: $+0.8 \pm 0.5$

Mean difference: $0.8 \pm 0.7 \quad P=0.3$

Ketones (expressed as acetone recovered)

Concentrations:

$\Delta \mathrm{mg} \%$, mean of control studies: $+\mathbf{0 . 3 6} \pm \mathbf{0 . 3 1}$

$\Delta \mathrm{mg} \%$, mean of stress studies: $-0.21 \pm 0.29$

Mean difference: $0.57 \pm 0.42 \quad P=0.2$

Rates:

$\Delta \mathrm{mg} / \mathrm{min}$., mean of control studies: $+0.0031 \pm 0.0030$

$\Delta \mathrm{mg} / \mathrm{min}$., mean of stress studies: $+0.0191 \pm 0.0082$

Mean difference: $0.0160 \pm 0.0088 \quad P=0.1$

Specific Gravity:

$\Delta$ Sp.Gr., mean of control studies: $+0.0002 \pm 0.0004$

$\Delta$ Sp.Gr., mean of stress studies: $-0.0078 \pm 0.0015$

Mean difference: $0.0080 \pm 0.0015 \quad P<0.002$

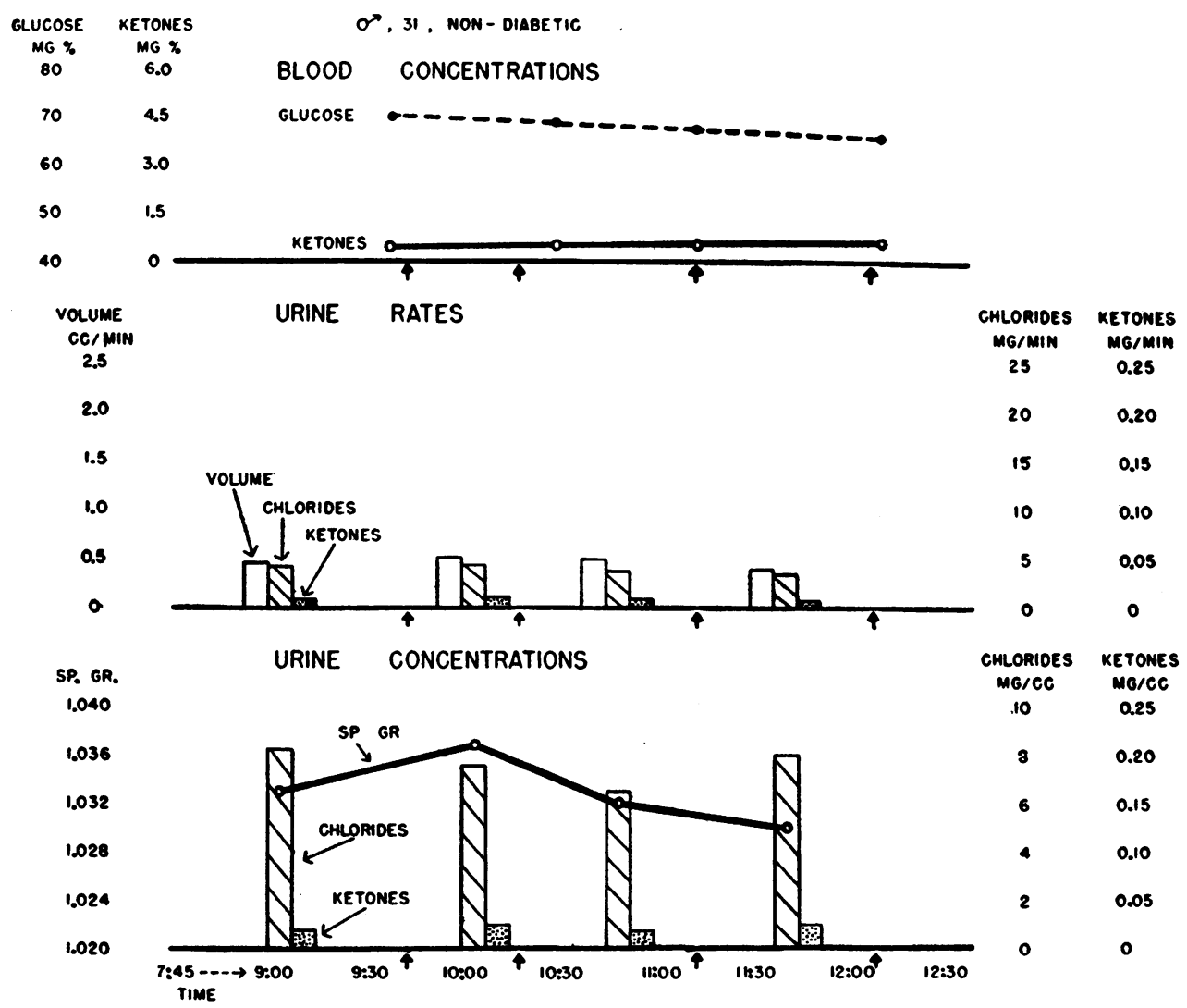

Fig. 1. Diagram of a Control Study, Showing Relatively little Change in Concentration of Blood Glucose and Krtones, in the Rate of Excretion of Water, Chlorides, and Ketones, and in the Concentration of These Substances in the Urine

Arrows on the diagram represent collection points. Interview took place during second hour. 


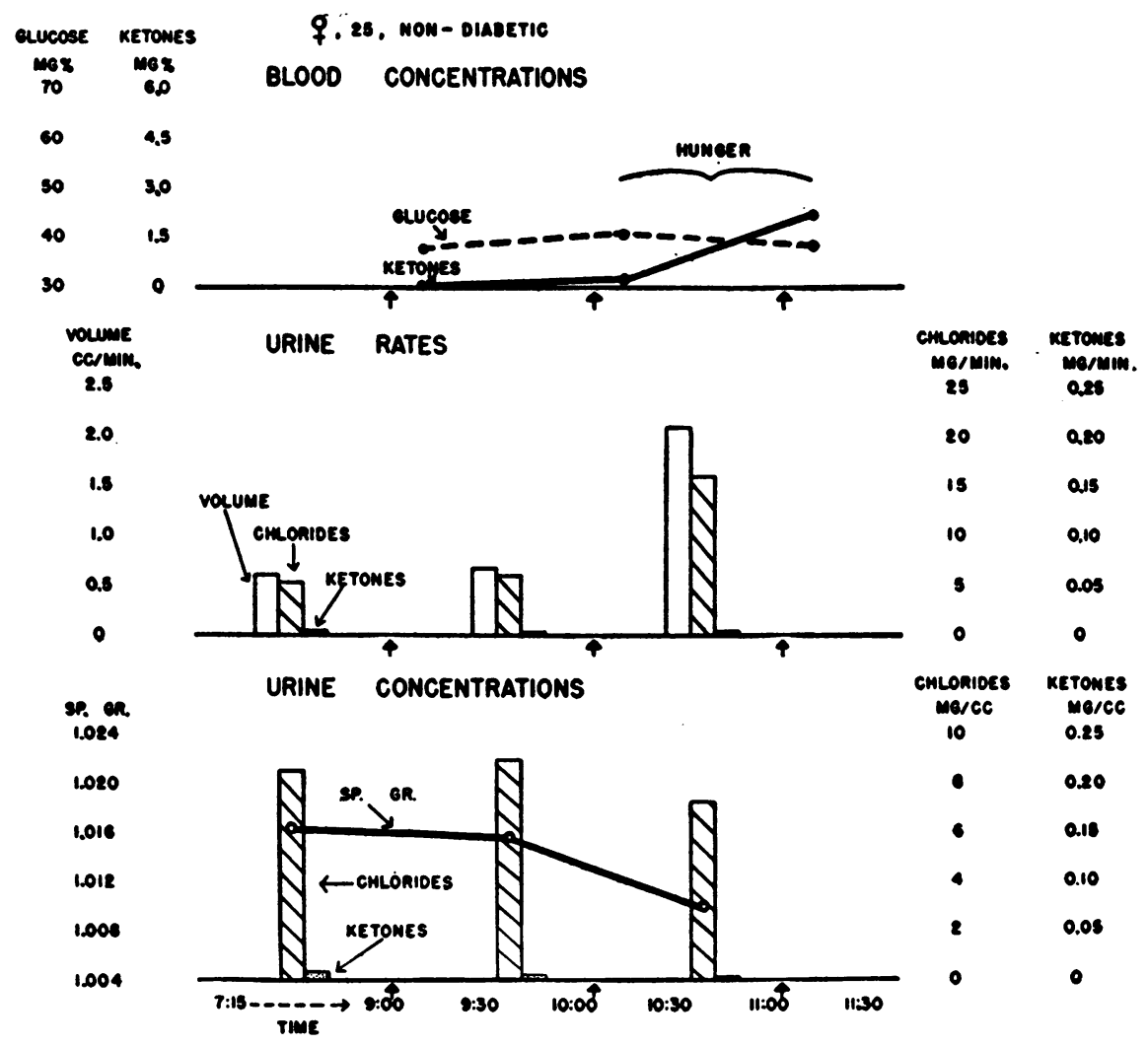

Fig. 2. Diagram of a Control. Study on a Subject Who Became Hungry during the Later Part of the Morning, Showing the Rise in Blood Ketones and the Diuresis Which Occurred at the Same Time

Subject was standing, walking about, doing routine laboratory work throughout the morning.

stages of the morning. This could not be related to changes in activity, position, or fluid intake, but it was associated with a pronounced hunger and a feeling of generalized tension. The rise in urine volume was accompanied by a fall in the specific gravity of the urine and in the concentration of ketones; because of this fall in concentration, the rate of ketone excretion was relatively unchanged. The chloride concentration fell relatively less, if at all ; because of this the diuresis was accompanied by a rise in chloride excretion. This diuresis was regularly accompanied by a rise in the concentration of the blood ketones, a fall in the blood glucose concentration, and a fall in the number of circulating eosinophiles. The changes in the blood constituents did not appear to be the cause of the diuresis, however, since they occurred also in some subjects who had no diuresis. The protocol of one of these studies is diagrammed in Figure 2.

\section{Stress Studies}

In 11 out of 12 subjects in whom intense conflicts were aroused a diuresis occurred (Table II). This was a diuresis of water, accompanied by a fall in the specific gravity of the urine and in the concentration of chloride (Table III). Because of the fall in chloride concentration, the rate of chloride excretion did not consistently change, although in some cases it rose. Accompanying the diuresis there was regularly a fall in the blood glucose and a rise in the blood ketones. A $50 \%$ to $80 \%$ fall in the number of circulating eosinophiles occurred in most of the stress experiments. In some instances the concentration of ketones in the urine fell, and the rate of ketone excretion remained relatively constant; in others, in whom there was a marked rise in the blood ketones, the ketone concentration in the urine and the rate of ketone 
excretion rose. The blood glucose and ketone and eosinophile levels are not included in the tables, but are dealt with in other papers $(23,30)$.

Periods of increased urine flow coincided with periods of more or less overt apprehension and anxiety in the subjects, and appeared to be related to specific personal conflicts only in the degree to which such conflicts aroused anxiety. Subject $B F$, for example, was notably depressed and angered during the discussion of the cruel treatment he received from his oppressive father, but we could find no evidence that the interview made him anxious. He was the only subject in the stress group who developed no diuresis. All of the other subjects were anxious during the interview, and had elevated rates of urine output during this time. But the discussion in itself was obviously not the only cause of the diuresis. It appeared that any anxiety-arousing situation might be associated with a diuresis. Subjects who became apprehensive when they were told that they would have a "special test," or when they were waiting for the interview to begin, had an elevated urine output during the initial hour; whereas those who were not apprehensive before the interview period had no diuresis until the interview began.

Subject AW, for example, was a business executive who had been hospitalized because of precordial pain, and who thought that he had a coronary occlusion. Although he had been told that this was not the case, he suspected that the physicians were only trying to reassure him. When he was told that on the next day he would have a "special test" he was suspicious that it was a "heart test" and would reveal severe heart disease. He slept poorly the night before, was apprehensive when awakened, and remained so all morning until the interview ended. At a later date, when he realized that he had no heart disease, and when the procedure represented no threat to him, he went through a physically identical experiment in a relatively tranquil state, and had no diuresis.

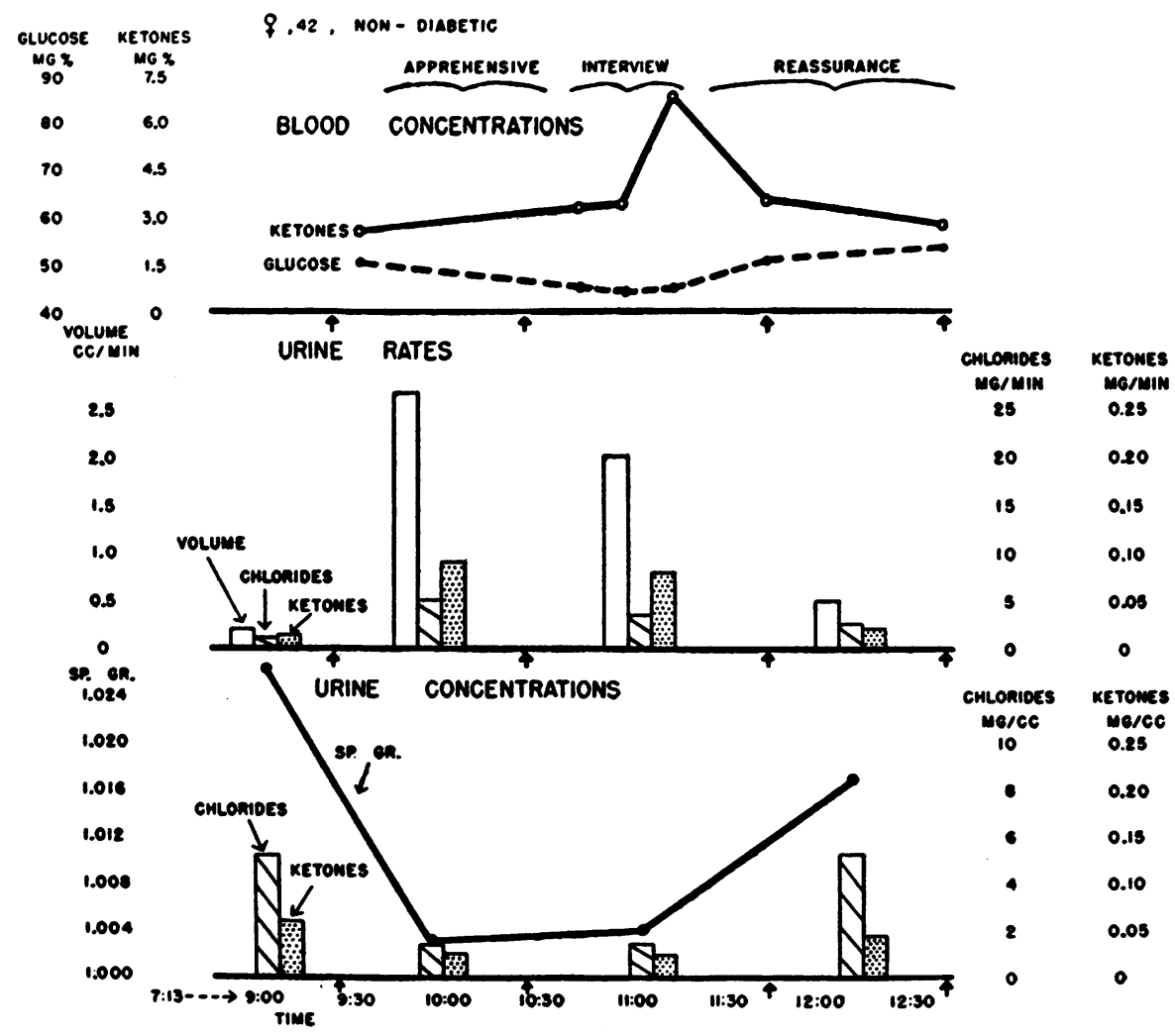

Fig. 3. The Diuresis Associated With a Stressful Life Situation, Showing Accompanying Changes in Blood Glucose and Ketone Concentration, and in the Concentration of Chlorides, Ketones, and Water in the Urine 
In describing the situations in which their urine flow was elevated, the subjects used terms such as "I didn't know what was going to happen," "I was worried about what you were going to do to me," "The way you acted made me nervous," or "I was nervous talking about mother like that." They were moderately to markedly apprehensive, rather than overwhelmingly afraid. None of them hyperventilated.

Illustrative of these findings is the case of a 42 year old business woman, a divorcee who complained of weakness and fatigue (Figure 3 ). On the day of the procedure she came in slightly late, expressing apprehension about what would be done. She quickly settled herself comfortably, however, and talked in a friendly and ostensibly calm manner about minor experiences of the day.

At the beginning of the second hour when she was asked to lie on the examining table her anxiety and apprehension recurred and became evidently more intense as the indwelling obturator needle was placed in her vein. "What are you doing?" she said with obvious alarm. Within approximately 15 minutes, in association with a discussion of frustrations in her job and resentment of her mother whom she was required to support, she expressed hostility mingled with depressive preoccupations. Finally, the evidence of depression predominated and she said, "You are going to an awful lot of trouble for me and I don't deserve it, I'm not used to that kind of treatment and I feel guilty. I'm not worth it." Throughout this middle hour the underlying anxiety and apprehension persisted, and although her manner was often deprecatory, she watched the periodic blood drawing procedure uncomfortably and said, "When do I get a transfusion?"

During the last hour she sat quietly, at first musing over depressive thoughts, and then became increasingly impatient to get done with the procedure and back to work. The findings in this case are presented diagrammatically in Figure 3, which shows a steep rise in urine flow during the period marked predominantly by anxiety and apprehension, associated with a precipitous fall in specific gravity and chloride concentration. It is also of interest that a rise in the concentration of blood ketones corresponded with the period of maximal evidence of resentment. That the changes in blood glucose and ketone concentration were not causally related to the changes in urine output are apparent from the fact that the diuresis took place before any significant change in the blood constituents occurred.

\section{DISCUSSION}

It is apparent that the rate of excretion of water in humans is sufficiently under the control of the central nervous system to allow the initiation of a diuresis as great as $4.5 \mathrm{cc} / \mathrm{min}$. in individuals who have received no fluids during the preceding 12 hours.

It has long been known that a transient diuresis may occur in some subjects during the earliest stages of a total fast $(18,31)$. This diuresis quickly subsides if the subject is totally starved, but in the partially starved person polyuria may be an outstanding symptom (19). It has been suggested that this diuresis may be advantageous in reducing the renal osmotic work and thereby reducing the consumption of energy producing substances by the kidney (32). Winkler and associates (31) felt that it might be the result of increased nitrogen excretion. However, its appearance in conjunction with a rise in the blood ketones and a fall in the blood glucose suggests that it may be a result of the metabolic rearrangements which take place as the organism shifts from carbohydrate to fat as a primary source of energy, as Gamble and his coworkers (18) first suggested. Presumably such a shift may make available a slight excess of body water which demands excretion. If these conjectures are correct, it may be that the diuresis which these subjects developed in a stressful situation is a part of a generalized metabolic response which is set in motion by an implied threat to the integrity of the organism.

The mechanism by which these changes are brought about is not clear. It seems possible that they may be the result of an inhibition of the secretion of the antidiuretic hormone by the posterior pituitary, leading to a decrease in the reabsorption of water by the distal tubule. The fall in circulating eosinophiles which coincided with the diuresis suggests that there may also have been an increased elaboration of the adrenal cortico-steroids. Circulating epinephrine would seem to be an inadequate explanation, because of the inconstant effect of this hormone on urine output, and the absence of obvious epinephrine effects in some 
subjects who had diuresis. Furthermore it cannot be ruled out that these changes in water excretion were the result of changes in renal hemodynamics. It has been shown that stressful situations may result in changes in renal blood flow, in glomerular filtration, and in the filtration fraction $(4,33)$. Although it is generally felt that changes in renal blood flow are not reflected in changes in urinary volume except under extreme circumstances (34), such conclusions have been drawn largely from clearance studies which were made at rates of urine flow $(3-10 \mathrm{cc} / \mathrm{min}$.) not usually seen in humans except after a great deal of water has been ingested. Other studies, made at lower rates of urine formation, suggest that under such conditions the volume of urine flow may be related to the renal blood flow and glomerular filtration (35).

In any case it is not possible to attribute the polyuria of stressful life situations entirely to the increased ingestion of water. It may even be that the increased water ingestion which occurs under such circumstances is the result of the thirst engendered by the diuresis. This phenomenon appears to be of special significance in individuals suffering from diabetes mellitus. In them it has been found that a profound diuresis occurring in reaction to life stress may be of great importance in the pathogenesis of the dehydration which is associated with some episodes of diabetic ketoacidosis. This subject will be discussed in a subsequent paper.

\section{CONCLUSIONS}

Stimuli, in the form of threatening life situations, acting through the highest integrative levels of the central nervous system, may lead to a spontaneous diuresis in hydropenic humans. This diuresis is characterized by a $200 \%$ to $500 \%$ increase in the urine volume, accompanied by a fall in the specific gravity of the urine, and a fall in the concentration chlorides. It is commonly accompanied by a rise in the concentration of ketone bodies in the blood and a moderate fall in the level of the blood glucose, but does not appear to be caused by changes in these blood constituents. In the presence of a large increase in the concentration of ketone bodies, the rate of ketone excretion in the urine may also rise; otherwise, there may be no increase in ketone excretion in association with the diuresis. Feelings of anxiety and apprehension were found to occur in company with the diuresis described.

\section{REFERENCES}

1. Rydin, H., and Verney, E. B., The inhibition of water diuresis by emotional stress and by muscular exercise. Quart. J. Exper. Physiol., 1938, 27, 343.

2. Verney, E. B., The anti-diuretic hormone and the factors which determine its release. Proc. Roy. Soc. London, Series B, 1947, 135, 25.

3. Kelsall, A. R., The inhibition of water diuresis in man by ischaemic muscle pain. J. Physiol., 1949, 109, 150.

4. Wolf, G. A., The effect of pain on renal function. A. Research Nerv. \& Ment. Dis., Proc., 1943, 23, 358.

5. Odell, L. D., and Aragon, G. T., In regard to the results of creatinine, hippurate, and inulin clearance estimations in rats. Science, 1947, 106, 265.

6. Dunbar, H. F., Emotions and Bodily Changes. Columbia Univ. Press, New York, 1938, Ed. 2, pp. 325-326.

7. Marx, H., Untersuchungen uber den Wasserhaushalt. II. Die Psychishe Beeinflussung des Wasserhaushalt. Klin. Wchnschr., 1926, 5, 92.

8. Heilig, R., and Hoff, H., Uber Hypnotishe Beeinflussung der Nierenfunktion. Deutsche med. Wchnschr., 1925, 51, 1615.

9. Hoff, H., and Wermer, P., Untersuchungen uber den Mechanismus der Diuresehemmung durch Pituitrin am Menschen. Arch. f. exper. Path. u. Pharmakol., 1926, 119, 153.

10. Marx, H.: Diuresis by conditioned reflex. Am. J. Physiol., 1931, 96, 356.

11. Bykow, K. M., and Alexejew-Berkmann, I. A., Die Ausbildung bedingter Reflexe auf die Harnausscheidung; and Ibid. II. Bedingte Reflexe bei denervierter Niere. Arch. f. d. ges. Physiol., 1930, 224, 710 ; and 1931, 227, 301.

12. Eagle, E., Conditioned inhibition of water diuresis. Am. J. Physiol., 1933, 103, 362.

13. Anderson, M., Diuresis by suggestion. Brit. M. J., 1946, 1, 776.

14. Rooke, A. B., Diuresis by suggestion. Brit. M. J., 1946, $1,589$.

15. Sheba, C., Personal communication to Dr. H. G. Wolff.

16. Hinkle, L. E., Evans, F. M., and Wolf, S., Studies in diabetes mellitus. III. The life history of three labile diabetics and the relation of significant experiences in their lives to the onset and course of the disease. Psychosomatic Med., 1951, 13, 160.

17. Hinkle, L. E., Edwards, C. J., and Wolf, S., Studies in diabetes mellitus. II. The occurrence of a diuresis in diabetic persons exposed to stressful life 
situations, with experimental observations on its relation to the concentration of glucose in blood and urine. J. Clin. Invest., 1951, 30, 818.

18. Gamble, J. L., Ross, G. S., and Tisdale, F. F., The metabolism of fixed base during fasting. J. Biol. Chem., 1923, 57, 633.

19. Keys, A., Brozek, J., Henschel, A., Mickelson, O., and Taylor, H. L., The Biology of Human Starvation. Univ. of Minn. Press, Minneapolis, 1950, Vol. I, Chap. 31, p. 664,

20. Sendroy, J., Jr., Photoelectric microdetermination of chloride in biological fluids, and of iodate and iodine in protein-free solutions. J. Biol. Chem., 1939, 130, 605.

21. Greenberg, L. A., and Lester, D., A micromethod for the determination of acetone and ketone bodies. J. Biol. Chem., 1944, 154, 177.

22. Lester, D., and Greenberg, L. A., The determination of acetone and ketone bodies. J. Biol. Chem., 1948, 174, 903.

23. Hinkle, L. E., Conger, G. B., and Wolf, S., Studies in diabetes mellitus: The relation of stressful life situations to the concentration of ketone bodies in the blood of diabetic and non-diabetic humans. J. Clin. Invest., 1950, 29, 754.

24. Benedict, S. R., The detection and estimation of glucose in urine. J. A. M. A., 1911, 57, 1193.

25. Herbert, F. K., and Bourne, M. C., The non-sugar reducing substances in human blood, with special reference to glutathione. Biochem. J., 1930, 24, 299.

26. Benedict, S. R., The determination of blood sugar. II. J. Biol. Chem., 1928, 76, 457.
27. Everett, M. R., Determination of sugar in blood. I. Observations up Benedicts's alkaline copper solution. J. Biol. Chem., 1929, 82, 369.

28. Benedict, S. R., The determination of sugar in blood. J. Biol. Chem., 1929, 83, 165.

29. Thorn, G. W., Forsham, P. H., Prunty, F. T. G., and Hills, A. C., A test for adrenal cortical insufficiency; response to pituitary adrenocorticotropic hormone. J.A.M.A., 1948, 137, 1005.

30. Hinkle, L. E., Wolf, S., and Greenberg, D., Unpublished data on the effect of stressful life situations on blood glucose and circulating eosinophiles.

31. Winkler, A. W., Danowski, T. S., Elkinton, J. R., and Peters, J. P., Electrolyte and fluid studies during water deprivation and starvation in human subjects and the effect of ingestion of fish, of carbohydrate and of salt solutions. J. Clin. Invest., 1944, 23, 807.

32. Keys, A., Brozek, J., Henschel, A., Mickelsen, O., and Taylor, H. L., op. cit., pp. 671-672.

33. Wolf, S., Pfeiffer, J. B., Ripley, H. S., Winter, O. S., and Wolff, H. G., Hypertension as a reaction pattern to stress: Summary of experimental data on variations in blood pressure and renal blood flow. Ann. Int. Med., 1948, 29, 1056.

34. Wolf, A. V., The Urinary Function of the Kidney. Grune \& Stratton, Inc., New York, 1950, p. 198.

35. Handley, C. A., Sigafoos, R. B., and LaForge, M., Proportional changes in renal tubular reabsorption of dextrose and excretion of p-aminohippurate with changes in glomerular filtration. Am. J. Physiol., 1949, 159, 175. 